\title{
Removal of potassium from aqueous system by lime loaded rice husk carbon
}

\author{
S.V. Sankaranarayanan ${ }^{1}$, N.Arumugam ${ }^{2}$ and S. Syed Shafi ${ }^{3 *}$ \\ ${ }^{I}$ Department of Chemistry, Alpha College of Engineering, Thirumazhisai, Chennai - 600124 \\ ${ }^{2}$ Department of Biology, Gandhigram Rural University, Gandhigram, Dindigul - 624302 \\ ${ }^{3}$ Department of Chemistry, Thiruvalluvar University, Vellore - 632115
}

\begin{abstract}
Removal of potassium is carried out by lime loaded rice husk carbon (LRHC). The extent of removal depends on initial concentration of potassium in solution, $p H$ of the solution, carbon dosage, temperature etc. As the concentration of potassium is increased, the removal of potassium is decreased. When the adsorbent dosage is increased from $1 \mathrm{~g}$ to $4 \mathrm{~g}$, the removal of potassium from the salt solution is increased. As the $\mathrm{pH}$ increased from 3 to 6 , the removal of potassium had been decreased. The amount of potassium removed increases from $\mathrm{pH} 6$ to 7. Freundlich and Langmuir adsorption isotherm models indicate the occurrence of adsorption. Thermodynamic parameters show the biosorption is endothermic and non-spontaneous. Kinetics shows the adsorption is first order reaction. IR spectrum indicates the adsorption is physisorption. SEM and EDX studies show the adsorption of potassium on the carbon.
\end{abstract}

Key words: Biosorption, Potassium, Kinetics, Rice husk, Sorption isotherm

\section{Introduction}

Minerals present in natural water plays key role in body functioning and bones formation. Metal ions like $\mathrm{Ca}^{2+}, \mathrm{Mg}^{2+}, \mathrm{Na}^{+}$and $\mathrm{K}^{+}$helps our nerves to work, our kidneys to filter blood, our muscles to move, prevention of blood pressure etc. These ions however in excess amounts can cause toxic effects. The discharge of metals into water is a major concern because they accumulate in living organisms resulting in various disorders. The problem of removing these pollutants from water is more important in developing countries. The water containing potassium compounds come from salts like potassium carbonate, potassium tartrate, potassium dichromate and potassium cyanide. Potassium is a metal commonly found in water. It is an essential nutrient required for treating high blood pressure and preventing stroke. It plays key role in body functions such as transmission of nerve signals, muscle contractions and fluid balance. It is used for treating and preventing low potassium levels in the blood, irregular heartbeats and heart attack. But its long term exposure can cause stomach upset, diarrhea, nausea, vomiting, paralysis, dizziness and death. Potassium can be removed from water by precipitation techniques, adsorption methods $[1,2]$, ion-exchange methods, electro dialysis, membrane techniques, solvent extraction and ion floatation methods. Among these methods, adsorption method is an economically feasible alternative.

\section{Procedure}

All reagents used in the experiments were of pure grade. The stock solution was prepared by dissolving chromic salt in requisite amount of water. The standard solutions of required concentration were prepared by dissolving stock solution with water. The $\mathrm{pH}$ of the suspensions is adjusted with $\mathrm{HCl}$ or $\mathrm{NaOH}$ to the required value. The rice husks [3] were dried and treated with $\operatorname{conH}_{2} \mathrm{SO}_{4}$. The mixture is washed with water and dried. The carbon obtained is called rice husk carbon. The rice husk carbon is soaked with $2 \%$ lime solution overnight and excess lime solutions were decanted off. The carbon thus prepared was called lime loaded rice husk carbon (LRHC). Batch experiments were performed to establish various parameters for the removal of potassium from aqueous solution. Different concentrations of adsorbate $(32.40 \mathrm{mg} / \mathrm{l}$ to $162.0 \mathrm{mg} / \mathrm{l})$ were added to $1 \mathrm{~g}$ of carbon (LRHC) with $\mathrm{pH} 3.0$ at $30^{\circ} \mathrm{C}$ and agitated in a mechanical shaker at $160 \mathrm{rpm}$ for $2 \mathrm{~h}$. These samples were filtered separately using filter paper. The filtrates were analyzed to determine the potassium concentration. Different adsorbent dosages ( $1 \mathrm{~g}$ to $4 \mathrm{~g}$ ) were added to $100 \mathrm{ml}$ of chromic salt solution with $\mathrm{pH} 3.0$ at $30^{\circ} \mathrm{C}$ and agitated in a mechanical shaker for $2 \mathrm{~h}$. The filtrates were analyzed for adsorption efficiency. The above data were interpreted using Freundlich adsorption isotherm and Langmuir adsorption isotherm. The salt solution of $100 \mathrm{ml}$ was added to $1 \mathrm{~g}$ of carbon (LRHC) at different $\mathrm{pH}$ values $(3$ to 7$)$ and agitated for $2 \mathrm{~h}$ at $30^{\circ} \mathrm{C}$. The filtrate was analyzed for adsorption efficiency. The salt solution of $100 \mathrm{ml}$ was added to $1 \mathrm{~g}$ of carbon (LRHC) at $30^{\circ} \mathrm{C}$ with $\mathrm{pH} 3.0$ and kinetic studies were carried out at different time intervals ( $1 \mathrm{~h}$ to $4 \mathrm{~h}$ ). Different concentrations of adsorbate were added to $1 \mathrm{~g}$ of carbon (LRHC) with $\mathrm{pH} 3.0$ and thermodynamics were studied for $2 \mathrm{~h}$ at different temperatures (303K to $333 \mathrm{~K}$ ). The filtrate was analyzed for equilibrium concentration and the data were interpreted for Van't Hoff isotherm, Van't Hoff isochore and Gibbs-Helmholtz equation. Infrared 
(IR) spectra of raw carbon sample and metal adsorbed carbon sample were taken from JASCO, FT-IR 4100. The concentration of potassium in the aqueous solution was analyzed by Inductively Coupled Plasma (ICP) method using Perkin Elmer Optima 5300 DV. Scanning Electron Microscope (SEM) and Energy - dispersive X - ray spectroscopy (EDX) of raw carbon sample and metal adsorbed carbon sample were taken from Sophisticated Analytical Instrument Facility (SAIF), IIT-Madras.

"3.1Effect of initial concentration"

\section{Results and Discussion}

The adsorption of potassium at different initial concentrations $[4,5]$ is shown in Table 1.

\begin{tabular}{|c|c|c|}
\hline Initial concentration, $\mathrm{C}_{\mathrm{o}}(\mathrm{mg} / \mathrm{l})$ & Adsorption capacity, $\mathrm{q}_{\mathrm{e}}(\mathrm{mg} / \mathrm{g})$ & Percentage removal of potassium \\
\hline 32.40 & 0.444 & 13.70 \\
\hline 64.80 & 0.385 & 5.94 \\
\hline 97.20 & 0.393 & 4.04 \\
\hline 129.60 & 0.030 & 0.23 \\
\hline 162.00 & 0.520 & 3.21 \\
\hline
\end{tabular}

Table 1 - Adsorption of potassium at different adsorbate concentration

Adsorption capacity is calculated using the equation (1).

$$
q_{e}=\frac{\left(\mathrm{C}_{\mathrm{o}}-\mathrm{C}_{\mathrm{e}}\right) \mathrm{V}}{1000 \mathrm{~m}}
$$

where $C_{o}$ is the initial concentration of metal ion $(\mathrm{mg} / \mathrm{l}), \mathrm{C}_{\mathrm{e}}$ is the equilibrium concentration of metal ion $(\mathrm{mg} / \mathrm{l}), \mathrm{m}$ is the mass of LRHC carbon $(\mathrm{g})$ and $\mathrm{V}$ is the volume of the sample $(\mathrm{ml})$. The adsorption of potassium on the solid phase of carbon is decreased with increase in concentration of the solution. The effect of initial concentration on percent removal of potassium is shown in Fig.1. The result indicates the removal of potassium is concentration dependent. LRHC carbon contains carbon and silica based material that binds the metal ion from the aqueous solution.

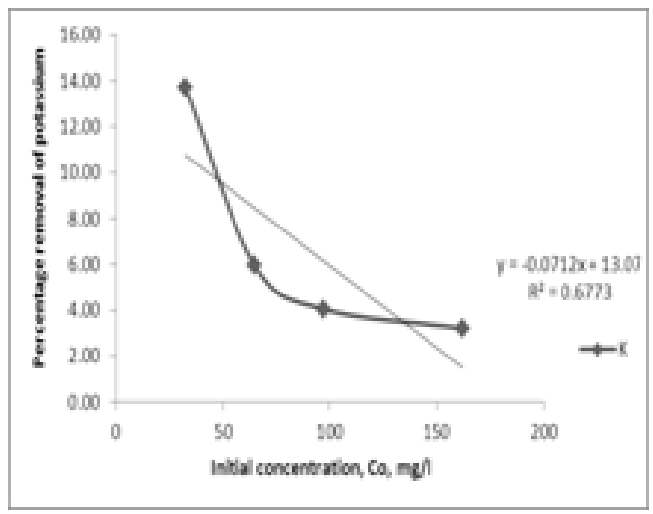

Fig. 1 Effect of adsorbate concentration on potassium removal, $1 \mathrm{~g}$ carbon, $\mathrm{pH} 3,30^{\circ} \mathrm{C}, 2 \mathrm{~h}$

\section{"3.2 Effect of adsorbent dosage"}

The variation of adsorbent dosage with adsorption capacity [6] is shown in Table 2.

Table 2 - Adsorption of potassium using different adsorbent dosage

\begin{tabular}{|c|c|c|}
\hline Adsorbent dosage (g) & Adsorption capacity, $\mathrm{q}_{\mathrm{e}}(\mathrm{mg} / \mathrm{g})$ & Percentage removal of potassium \\
\hline 1 & 0.444 & 13.70 \\
\hline 2 & 0.272 & 16.76 \\
\hline 3 & 0.266 & 24.66 \\
\hline 4 & 0.227 & 27.96 \\
\hline
\end{tabular}

The adsorption capacity decreases with increase in adsorbent dosage. This indicates that the adsorption capacity is less at higher adsorbent dosage. When the adsorbent dosage increased from $1 \mathrm{~g}$ to $4 \mathrm{~g} / 100 \mathrm{ml}$, the amount of potassium removed from the salt solution increased. The effect of adsorbent dosage on percent 
removal of potassium is shown in Fig.2. With increase in adsorbent dosage, more surface area is available for adsorption due to increase in active sites on the adsorbent.

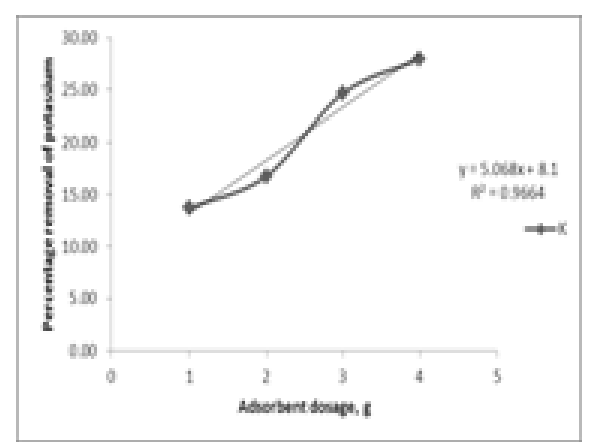

Fig 2 Effect of Adsorbent dosage on potassium removal, $32.40 \mathrm{mg} / 1$ potassium, $30^{\circ} \mathrm{C}, \mathrm{pH} 3,2 \mathrm{~h}$

\section{"3.3 Adsorption isotherms"}

Adsorption isotherms in solution indicate the relationship between the amount adsorbed and concentration at constant temperature. Freundlich adsorption isotherm was shown in Fig.3. The adsorption equilibrium is explained by the equation $\mathrm{q}_{\mathrm{e}}=\mathrm{K}_{\mathrm{F}} \mathrm{C}_{\mathrm{e}}{ }^{1 / \mathrm{n}}$ where $\mathrm{q}_{\mathrm{e}}$ is the adsorption capacity (mg/g) [(i.e.) amount of metal ion adsorbed per unit weight of LRHC carbon at equilibrium], $\mathrm{K}_{\mathrm{F}}$ is the constant, and $1 / \mathrm{n}$ is the constant which measures the strength of adsorption. The straight line obtained by plotting $\mathrm{q}_{\mathrm{e}}$ and $\mathrm{C}_{\mathrm{e}}$ indicate the increase in adsorption with increase in the equilibrium concentration of potassium. The adsorption equilibrium can also be explained by the following equation (2)

$$
\log \mathrm{q}_{\mathrm{e}}=\log \mathrm{K}_{\mathrm{F}}+\frac{1}{\mathrm{n}} \log \mathrm{C}_{\mathrm{e}}
$$

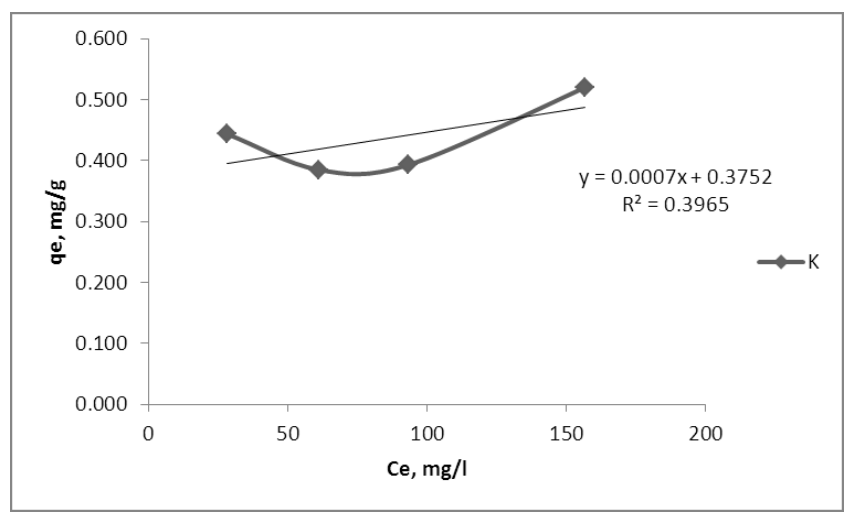

Fig 3 Freundlich adsorption isotherm of different equilibrium concentration of potassium

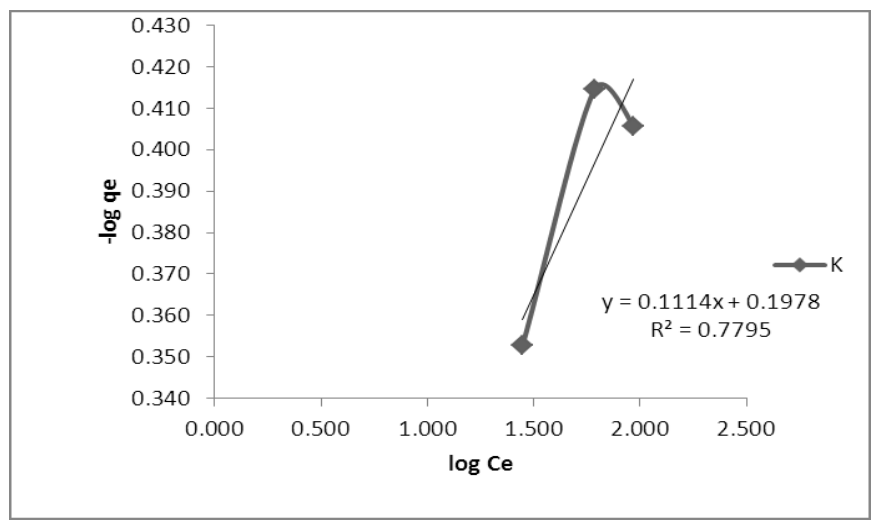

Fig 4 Freundlich isotherm showing effect of concentration of potassium 

below.

The values of Freundlich's constant and correlation coefficients $\left(\mathrm{R}^{2}\right)$ derived from Fig.4 are presented $\mathrm{n}=\frac{1}{\text { slope }}=8.977, \mathrm{~K}_{\mathrm{F}}=$ antilog of intercept $=1.577$ and $\mathrm{R}^{2}=0.7795$. The values of $\mathrm{n}$ from 1 to 10 represent favorable adsorption.

Langmuir adsorption isotherm [7] was shown in equation (3)

$$
\frac{\mathrm{C}_{e}}{\mathrm{q}_{\mathrm{e}}}=\frac{1}{\mathrm{ab}}+\frac{\mathrm{C}_{e}}{\mathrm{a}}
$$

where $\mathrm{a}$ is the constant for monolayer adsorption capacity $(\mathrm{mg} / \mathrm{g})$ and $\mathrm{b}$ is the constant for energy of adsorption ( $1 / \mathrm{g}$ ). The equilibrium data for potassium at fixed adsorbent dosage and varying potassium concentrations had been given in Fig.5.

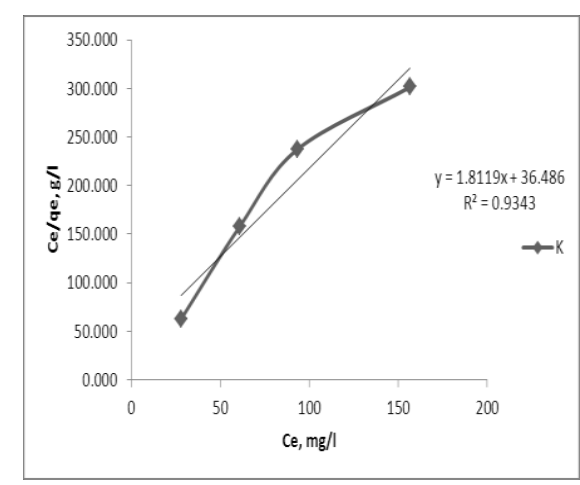

Fig 5 Langmuir adsorption isotherm of different equilibrium concentration for potassium

The linear plot of $\mathrm{C}_{\mathrm{e}} / \mathrm{q}_{\mathrm{e}}$ versus $\mathrm{C}_{\mathrm{e}}$ regression analysis at different initial concentrations indicated the applicability of Langmuir adsorption isotherm. The values of adsorption capacity and energy of adsorption along with regression coefficients $\left(\mathrm{R}^{2}\right)$ calculated from the slope and intercept are given below.

$$
\mathrm{a}=\frac{1}{\text { slope }}=0.5519, \mathrm{~b}=\frac{\text { slope }}{\text { intercept }}=0.0497 \text { and } \mathrm{R}^{2}=0.9343
$$

The results show that adsorption of potassium decreases with increase in concentrations of potassium. The ratio of the initial concentration of potassium ion in solution to the available sites on the carbon surface is low in lower concentration. As the concentration of potassium increases, the available sites on the carbon surface become fewer. The essential characteristics and the feasibility of Langmuir adsorption isotherm is expressed in terms of a dimensionless constant equilibrium parameter $\mathrm{R}_{\mathrm{L}}$, which is defined as

$$
\mathrm{R}_{\mathrm{L}}=\frac{1}{1+\mathrm{bc}_{\mathrm{o}}}=0.03831
$$

The $\mathrm{R}_{\mathrm{L}}$ values [8] between 0 and 1 indicate favourable adsorption. The $\mathrm{R}_{\mathrm{L}}$ value for the adsorption of potassium at different initial concentration represents a favourable adsorption for a given adsorbent. Langmuir isotherm for different adsorbent dosage is given in Fig.6.

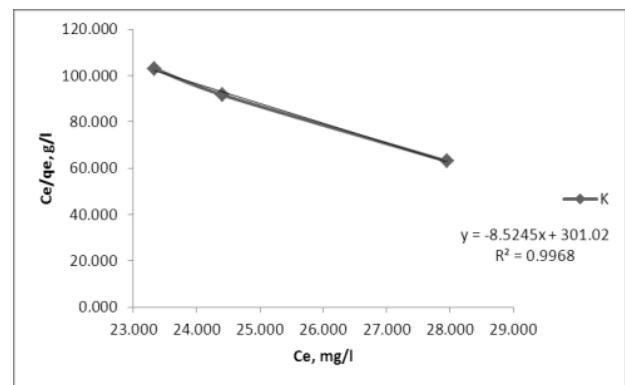

Fig 6 Langmuir adsorption isotherm of different adsorbent dosage 
The values of constants and correlation coefficients $\left(\mathrm{R}^{2}\right)$ are presented below.

$$
\mathrm{a}=\frac{1}{\text { slope }} \quad=0.1173, \mathrm{~b}=\frac{\text { slope }}{\text { intercept }}=0.0283 \text { and } \mathrm{R}^{2}=0.9968
$$

The linear plot indicates the applicability of Langmuir adsorption isotherm.

\section{"3.4 Effect of pH"}

The $\mathrm{pH}$ of a solution is an important factor which controls the process of adsorption. $\mathrm{pH}$ influences the surface charge of the adsorbent [9] and the degree of ionization. As the $\mathrm{pH}$ increased from $3 \mathrm{~g}$ to $6 \mathrm{~g}$, the amount of potassium removed from the salt solution decreased. The amount of potassium removed increases from $\mathrm{pH} 6$ to 7 . The variation of adsorption capacity with $\mathrm{pH}$ is given in the Table 3 .

Table 3 - Adsorption of potassium at different $\mathrm{pH}$

\begin{tabular}{|c|c|c|}
\hline $\mathrm{pH}$ & Adsorption capacity, $\mathrm{q}_{\mathrm{e}}(\mathrm{mg} / \mathrm{g})$ & Percentage removal of potassium \\
\hline 3 & 0.444 & 13.70 \\
\hline 4 & 0.379 & 11.70 \\
\hline 5 & 0.363 & 11.20 \\
\hline 6 & 0.241 & 7.44 \\
\hline 7 & 0.337 & 10.40 \\
\hline
\end{tabular}

The percentage removal of potassium with increase in $\mathrm{pH}$ is illustrated in Fig.7.

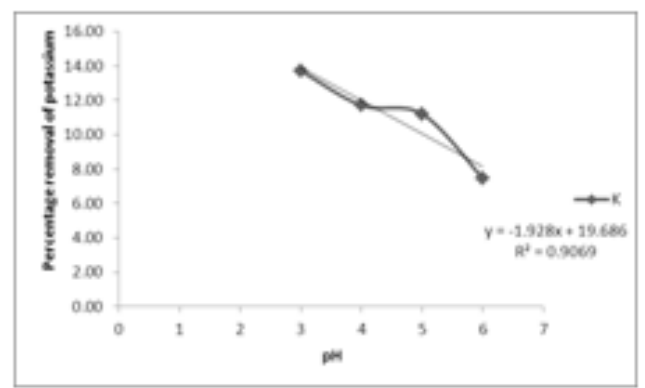

Fig 7 Effect of $\mathrm{pH}$ on potassium removal, $32.40 \mathrm{mg} / 1$ potassium, $1 \mathrm{~g}$ carbon, $30^{\circ} \mathrm{C}, 2 \mathrm{~h}$

The results show that the \% removal of potassium decreases from $\mathrm{pH} 3$ to 6 which indicates the adsorption is less in acidic solution. The \% removal increases from $\mathrm{pH} 6$ to 7 which shows the adsorption is more in neutral solution. The principal driving force for metal ion biosorption is the electrostatic interaction between adsorbent and adsorbate. When the interaction is more the biosorption is more [10].

\section{"3.5 Kinetic study"}

Kinetics study [11] was carried out to see the effect of time factor up to $4 \mathrm{~h}$ at different initial potassium concentration on the potassium removal. Adsorption of potassium at different time interval has been described in Table 4.

Table 4 - Adsorption of potassium at different time interval

\begin{tabular}{|c|c|c|}
\hline Time $(\mathrm{min})$ & Percentage removal of potassium & Rate constant, $\mathrm{K}_{\mathrm{ads}}\left(\mathrm{min}^{-1}\right)$ \\
\hline 60 & 7.93 & 0.07925 \\
\hline 120 & 13.70 & 0.03453 \\
\hline 180 & 15.40 & 0.02226 \\
\hline 240 & 14.10 & 0.01712 \\
\hline
\end{tabular}

$$
\mathrm{K}_{\mathrm{ads}}=\frac{2.303 \log \frac{\mathrm{q}_{\ominus}}{\mathrm{C}_{\Theta}}}{\mathrm{t}}
$$

By using equation (4), the rate constant $\left(\mathrm{K}_{\mathrm{ads}}\right)$ was calculated as 0.03829 . As the agitation time increased from $1 \mathrm{~h}$ to $4 \mathrm{~h}$, the $\%$ removal of potassium was increased up to $3 \mathrm{~h}$ and then decreased. The effect of time on percentage removal of potassium was shown in Fig.8. 


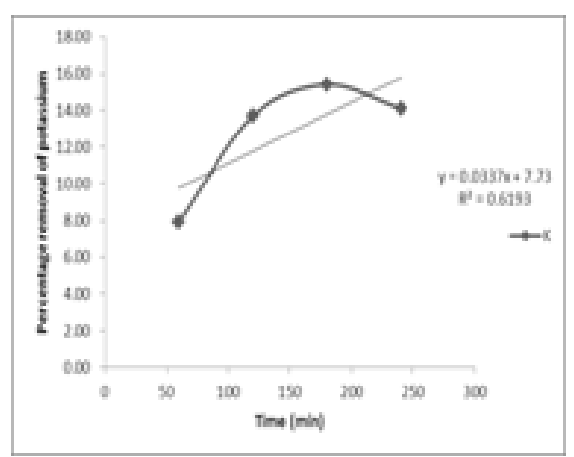

Fig 8 Effect of time on potassium removal, $32.40 \mathrm{mg} / 1$ potassium, $1 \mathrm{~g}$ carbon, $30^{\circ} \mathrm{C}, \mathrm{pH} 3$

This indicates that the maximum adsorption of potassium takes place at time interval of $3 \mathrm{~h}$. The equation (4) can be re written as equation (5).

$$
\log \frac{\mathrm{q}_{\mathrm{e}}}{\mathrm{C}_{\mathrm{e}}}=\frac{K_{a d s} \mathrm{t}}{2.303}
$$

The plot between $\log \left(\mathrm{q}_{\mathrm{e}} / \mathrm{C}_{\mathrm{e}}\right)$ and time interval was given in Fig.9.

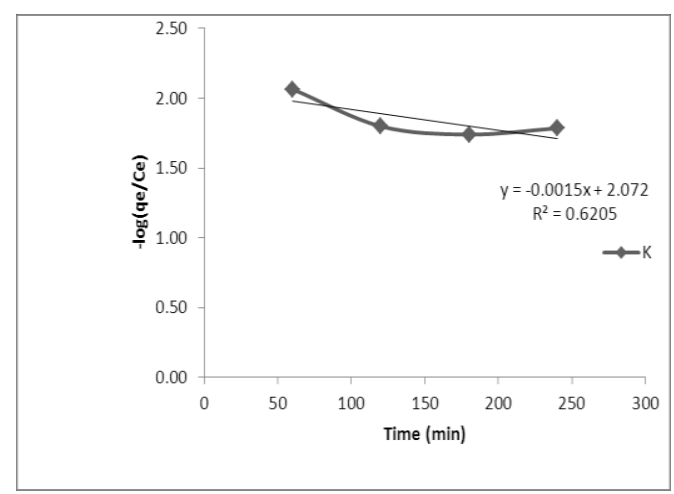

Fig 9 Chemical kinetics study $-\log \left(\mathrm{q}_{\mathrm{e}} / \mathrm{C}_{\mathrm{e}}\right)$ Vs time

The linearity of the plot indicates the reaction is of first order. The adsorption results for Lagergren first order equation [12] are shown in the Table 5.

Table 5 - Adsorption of potassium at different time interval using Lagergren equation

\begin{tabular}{|c|c|c|}
\hline Time (min) & Adsorption capacity, q (mg/g) & Rate constant, $\mathrm{K}_{\mathrm{ads}}\left(\mathrm{min}^{-1}\right)$ \\
& & \\
\hline 60 & 0.257 & 0.01206 \\
\hline 120 & 0.444 & 0.01838 \\
\hline 240 & 0.457 & 0.01031 \\
\hline
\end{tabular}

First order rate law derived by Lagergren is

$$
\mathrm{K}_{\mathrm{ads}}=\frac{2.303}{\mathrm{t}} \log \frac{\mathrm{q}_{\mathrm{\theta}}}{\mathrm{q}_{\mathrm{\theta}}-\mathrm{q}}
$$

By using equation (6), the rate constant $\left(\mathrm{K}_{\mathrm{ads}}\right)$ was calculated as 0.0136 . The equation (6) can be rewritten as equation (7).

$$
\log \left(\mathrm{q}_{\mathrm{e}}-\mathrm{q}\right)=\log \mathrm{q}_{\mathrm{e}}-\frac{\mathrm{K}_{\mathrm{ads}} \mathrm{t}}{2.303}
$$

Lagergren plot of $\log \left(\mathrm{q}_{\mathrm{e}}-\mathrm{q}\right)$ versus time was shown in Fig.10. 


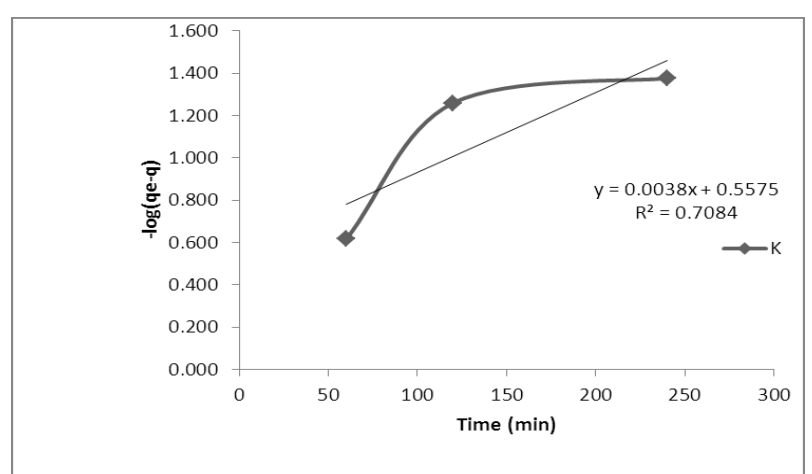

Fig 10 Lagergren first order equation

The linearity of these plots indicates that a first order mechanism is followed in this process. Correlation coefficient $\left(\mathrm{R}^{2}\right)$ was calculated as 0.7084 . The above results indicate the removal process is fast on the carbon surface and the percent removal increased with an increase in agitation time. This shows the reaction is of first order.

\section{"3.6 Thermodynamics"}

The changes occurred during biosorption can be explained by the three main important thermodynamic parameters [13] namely enthalpy change $(\Delta \mathrm{H})$, free energy change $(\Delta \mathrm{G})$ and entropy change $(\Delta \mathrm{S})$.

\subsubsection{Van't Hoff isotherm}

Van't Hoff isotherm [14] illustrates the relationship between free energy change and equilibrium constant. Gibbs free energy change $(\Delta \mathrm{G})$ is given by

$$
\Delta \mathrm{G}=-2.303 \mathrm{R} T \log \mathrm{K}(8) \text { where } \mathrm{K} \text { is the equilibrium constant. }
$$

\subsubsection{Gibbs-Helmholtz equation}

Gibbs-Helmholtz equation [15] gives the relationship between free energy change with temperature. Entropy change $(\Delta S)$ is given by

$$
\Delta S=-\frac{\partial(\Delta G)}{\partial T}
$$

\subsubsection{Van't Hoff isochore}

The quantitative effect of temperature on chemical equilibrium is given by Van't Hoff isochore [16]. Enthalpy change $(\Delta \mathrm{H})$ is given by

$$
\Delta \mathrm{H}=\frac{2.303 \mathrm{R} \mathrm{T}_{1} \mathrm{~T}_{2}\left(\log \mathrm{K}_{2}-\log \mathrm{K}_{1}\right)}{\mathrm{T}_{2}-\mathrm{T}_{1}}
$$

\subsubsection{Gibb's equation.}

Gibb's equation describes the relationship between free energy change, enthalpy change and entropy change. The values of $\Delta \mathrm{G}, \Delta \mathrm{H}$ and $\Delta \mathrm{S}$ calculated by using equation (8), equation (9) and equation (10) are substituted in the Gibb's equation (11) and it is satisfied.

$$
\Delta \mathrm{G}=\Delta \mathrm{H}-\mathrm{T} \Delta \mathrm{S} \quad(11)
$$

Table 6 Adsorption of potassium at different temperatures $\left(\mathrm{C}_{\mathrm{o}}=32.40 \mathrm{mg} / \mathrm{l}\right)$

\begin{tabular}{|c|c|c|c|}
\hline Temperature (K) & $\Delta \mathrm{G}(\mathrm{kJ} / \mathrm{mol})$ & $\Delta \mathrm{H}(\mathrm{kJ} / \mathrm{mol})$ & $\Delta \mathrm{S}(\mathrm{J} / \mathrm{mol})$ \\
& & & \\
\hline 303 & 10.438 & - & - \\
\hline 313 & 11.095 & -9.462 & -65.675 \\
\hline 323 & 15.387 & -64.547 & -247.474 \\
\hline 333 & 15.037 & -36.013 & -153.303 \\
\hline
\end{tabular}


Table 7 Adsorption of potassium at different temperatures $\left(\mathrm{C}_{\mathrm{o}}=162.0 \mathrm{mg} / \mathrm{l}\right)$

\begin{tabular}{|c|c|c|c|}
\hline mperature $(\mathrm{K})$ & $\Delta \mathrm{G}(\mathrm{kJ} / \mathrm{mol})$ & $\Delta \mathrm{H}(\mathrm{kJ} / \mathrm{mol})$ & $\Delta \mathrm{S}(\mathrm{J} / \mathrm{mol})$ \\
\hline 303 & 14.384 & - & - \\
\hline 313 & 14.911 & -1.582 & -52.692 \\
\hline 323 & 13.794 & 23.320 & 29.492 \\
\hline 333 & 13.370 & 24.628 & 33.807 \\
\hline
\end{tabular}

For initial concentration of $32.4 \mathrm{mg} / \mathrm{l}$, the values got for $\Delta \mathrm{G}, \Delta \mathrm{H} \& \Delta \mathrm{S}$ at different temperatures are given by $12.989 \mathrm{~kJ} / \mathrm{mol},-36.674 \mathrm{~kJ} / \mathrm{mol} \&-155 \mathrm{~J} / \mathrm{mol}$. This was shown in Table 6 . For initial concentration of $162 \mathrm{mg} / \mathrm{l}$, the values got for $\Delta \mathrm{G}, \Delta \mathrm{H} \& \Delta \mathrm{S}$ at different temperatures are given by $14.115 \mathrm{~kJ} / \mathrm{mol}, 15.455 \mathrm{~kJ} / \mathrm{mol}$ \& $3.536 \mathrm{~J} / \mathrm{mol}$. This was shown in Table 7 . The Gibbs free energy change is positive $(\Delta \mathrm{G}>0)$ which shows the biosorption is non-spontaneous. The LRHC carbon is preheated to expel the moisture and hence cavities are created. The change in entropy below zero $(\Delta \mathrm{S}<0)$ at lower temperatures and above zero $(\Delta \mathrm{S}>0)$ at higher temperatures indicate the process is irreversible and the affinity of adsorbent material for potassium ions. The negative value of heat of the reaction $(\Delta \mathrm{H}<0)$ at lower temperature indicates that biosorption is exothermic and it can liberate energy without any external aid. The positive value of heat of the reaction $(\Delta H>0)$ at higher temperature indicates that biosorption is endothermic. So, the percentage removal of potassium decreases with increase in temperature at lower concentration and increases with increase in temperature at higher concentration. These values illustrate the occurance of significant change in the internal structure of the adsorbent during adsorption.

\subsubsection{The effect of temperature on adsorption}

The effect of temperature on percentage removal of potassium is given in Fig.11. When the temperature is increased from $303 \mathrm{~K}$ to $333 \mathrm{~K}$, the percentage removal of potassium decreased.

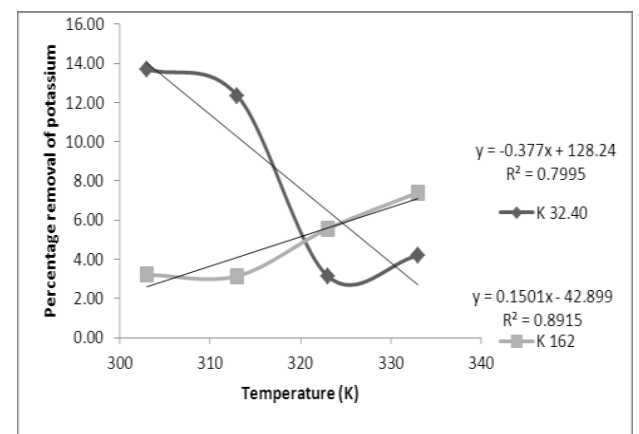

Fig 11 Effect of Temperature on potassium removal, $32.40 \mathrm{mg} / 1$ potassium, $1 \mathrm{~g}$ carbon, $\mathrm{pH} \mathrm{3,} 2 \mathrm{~h}$

The activation energy for potassium adsorption [17] was calculated using Arrhenius equation is given in equation (12).

$$
\mathrm{k}=\mathrm{A} \mathrm{e}^{-\mathrm{Ea} / \mathrm{RT}}(12)
$$

where $\mathrm{k}$ is rate constant at temperature of $\mathrm{T}(\mathrm{K}), \mathrm{R}$ is universal gas constant $\left(8.314 \mathrm{Jmol}^{-1} \mathrm{~K}^{-1}\right)$ and $\mathrm{E}_{\mathrm{a}}\left(\mathrm{Jmol}^{-1}\right)$ is activation energy for process. $\mathrm{A}$ is the total number of collisions per second, independent of temperature and called as frequency factor. The factor $\mathrm{e}^{-\mathrm{Ea} / \mathrm{RT}}$ is the probability that any given collision will result in a reaction.

$$
\log \mathrm{k}=\log \mathrm{A}-\frac{\mathbf{E}_{\mathbf{a}}}{2.303 \mathbf{R T}}
$$

The effect of temperature on rate constant was given in Fig. 12.

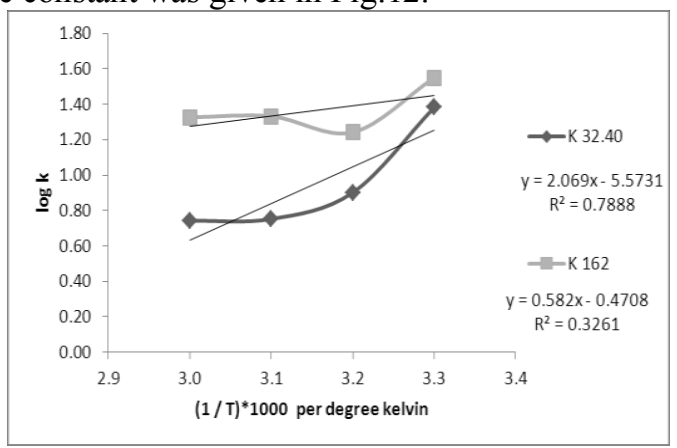

Fig 12 Effect of Temperature on equilibrium constant using Van't Hoff isochore 
By using logarithm, the equation (12) can be rewritten as equation (13). The $\mathrm{E}_{\mathrm{a}}$ value calculated from the slope of the plot for initial concentrations $32.40 \mathrm{mg} / 1$ and $162.0 \mathrm{mg} / \mathrm{l}$ are given by $39.62 \mathrm{kJmol}^{-1}$ and $11.14 \mathrm{kJmol}^{-1}$. This indicates the chemical nature of the adsorption. $\mathrm{E}_{\mathrm{a}}$ value below $42.00 \mathrm{~kJ} / \mathrm{mol}$ indicates diffusion controlled process and higher values represent surface controlled process.

\section{“3.7 FT-IR Study"}

The Fourier Transform - Infrared spectra [18] of raw LRHC and metal ion loaded LRHC are given in Fig. 13 and Fig.14.

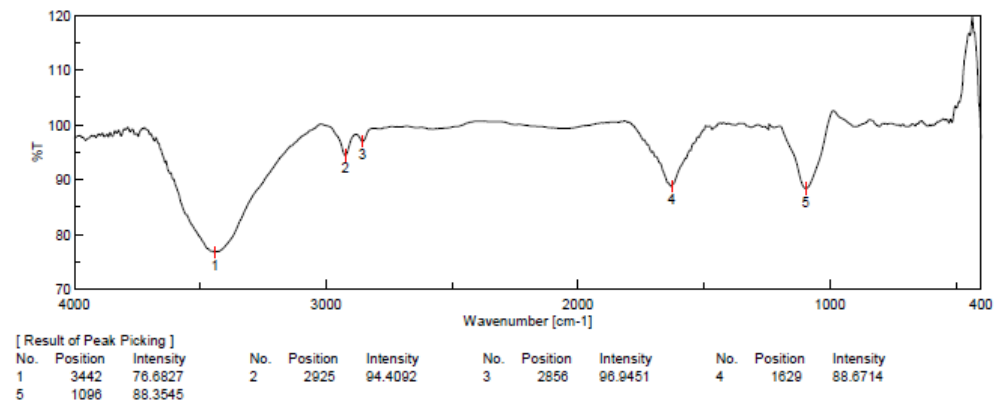

Fig 13 IR spectra of raw activated Carbon

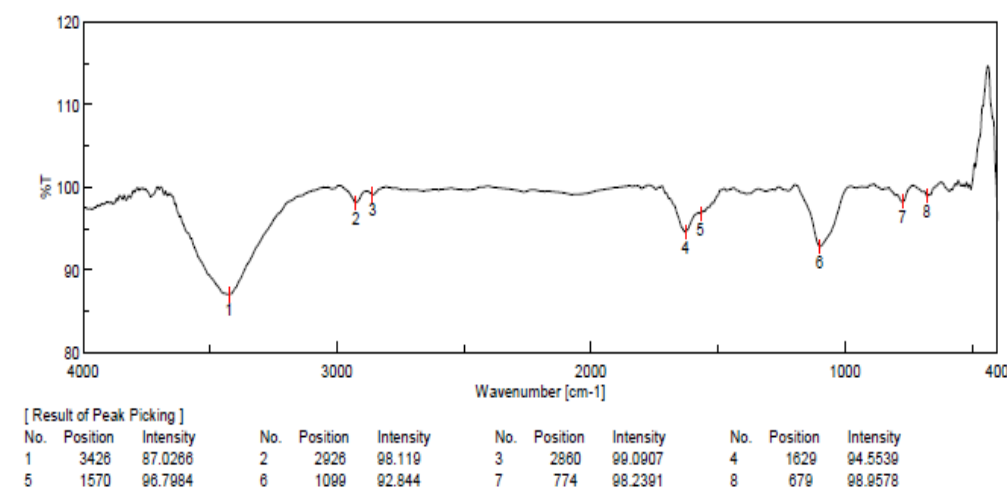

Fig 14 IR spectra of treated activated Carbon

\section{"3.8 SEM and EDX study"}

The scanning electron microscope (SEM) images [19] of the raw activated carbon taken at magnitude 1000x were given in Fig. 15.

They are recorded to understand the nature of adsorption. It is evident from the spectra that the positions of the spectra remain unaltered after the adsorption of metal ion from the solution. This indicates the chemical nature of adsorbent remains unaffected. Thus the adsorption of metal ions on the adsorbent is by physical forces only and not by chemical forces which might alter the chemical nature of the adsorbent and consequently the position of the peaks.

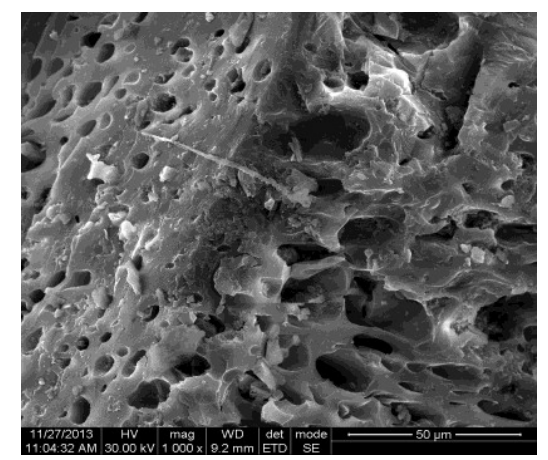

Fig 15 SEM image of raw activated carbon showing the presence of cavities 
The bright spots show the presence of tiny holes on the crystalline structure of raw activated carbon. Energy - dispersive X - ray spectroscopy (EDX) analysis of the raw activated carbon was shown in Fig.16.

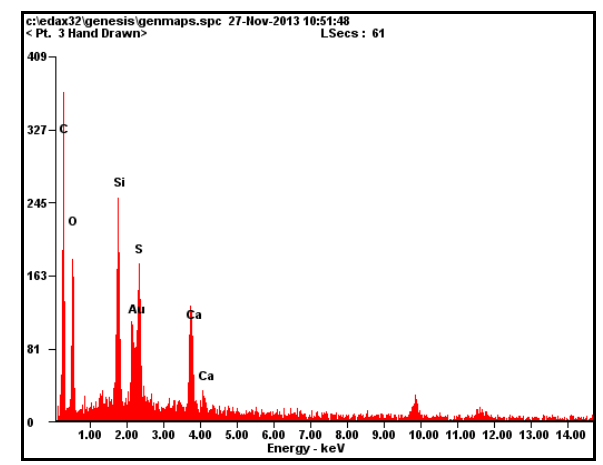

Fig 16 EDX analysis of raw activated carbon

It shows the absence of potassium. Elemental analysis of raw activated carbon was shown in Table 8 .

Table 8 - Percentage composition of elements in raw activated carbon

\begin{tabular}{|c|c|c|}
\hline Element & $\mathrm{Wt} \%$ & $\mathrm{At} \%$ \\
\hline $\mathrm{CK}$ & 60.45 & 72.92 \\
\hline $\mathrm{OK}$ & 24.77 & 22.43 \\
\hline $\mathrm{SiK}$ & 3.87 & 1.99 \\
\hline $\mathrm{AuM}$ & 5.36 & 0.39 \\
\hline $\mathrm{SK}$ & 2.78 & 1.26 \\
\hline $\mathrm{CaK}$ & 2.78 & 1.00 \\
\hline Matrix & Correction & $\mathrm{ZAF}$ \\
\hline
\end{tabular}

It indicates the $\%$ composition of various elements and indicates the absence of potassium. The SEM images of the metal adsorbed activated carbon taken at magnitude 1000x are given in Fig. 17.

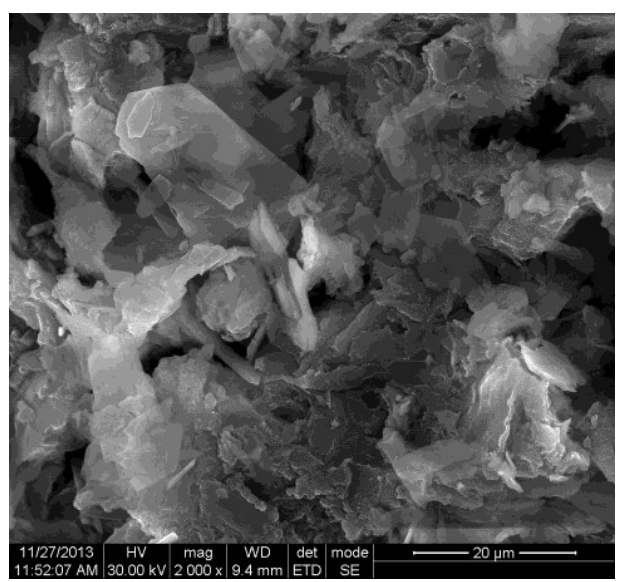

Fig 17 SEM image of treated activated carbon showing the presence of elements filled in cavities.

After treatment with metal ions the bright spots become black indicating the adsorption of metal ions on the surface of the carbon. EDX analysis of the metal adsorbed activated carbon was shown in Fig.18.

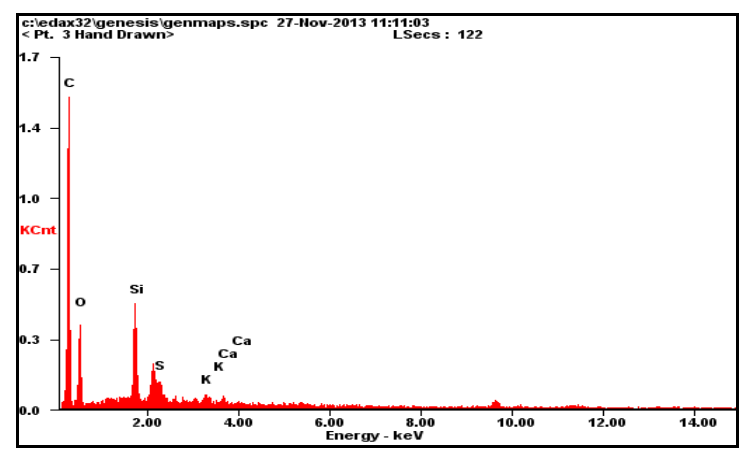

Fig 18 EDX analysis of treated activated carbon 
It indicates the presence of potassium. Elemental analysis of treated activated carbon was shown in Table 9.

Table 9 - Percentage composition of elements in treated activated carbon

\begin{tabular}{|c|c|c|}
\hline Element & $\mathrm{Wt} \%$ & $\mathrm{At} \%$ \\
\hline $\mathrm{CK}$ & 73.97 & 80.39 \\
\hline $\mathrm{OK}$ & 21.75 & 17.74 \\
\hline $\mathrm{SiK}$ & 2.97 & 1.38 \\
\hline $\mathrm{SK}$ & 0.69 & 0.28 \\
\hline $\mathrm{KK}$ & 0.34 & 0.11 \\
\hline $\mathrm{CaK}$ & 0.29 & 0.10 \\
\hline Matrix & Correction & $\mathrm{ZAF}$ \\
\hline
\end{tabular}

It indicates the $\%$ composition of potassium $(0.34 \%)$. This shows the adsorption of potassium on the activated carbon.

\section{Conclusion}

Lime loaded rice rusk carbon is an adsorbent for the removal potassium ions from the salt solution. The percentage removal increases with increase in adsorbent dosage and decreases with increase in adsorbate concentration. The maximum removal of potassium was found at $\mathrm{pH} 3$. The result was supported by the study of Freundlich \& Langmuir isotherm. Kinetics shows the adsorption is of first order. Thermodynamics show the adsorption is feasible. FT-IR shows the adsorption is physical nature. SEM \& EDX studies illustrate the adsorption process. It may be concluded that lime loaded rice rusk carbon may be used as a low cost, natural and abundant resource for the removal potassium ions from aqueous system.

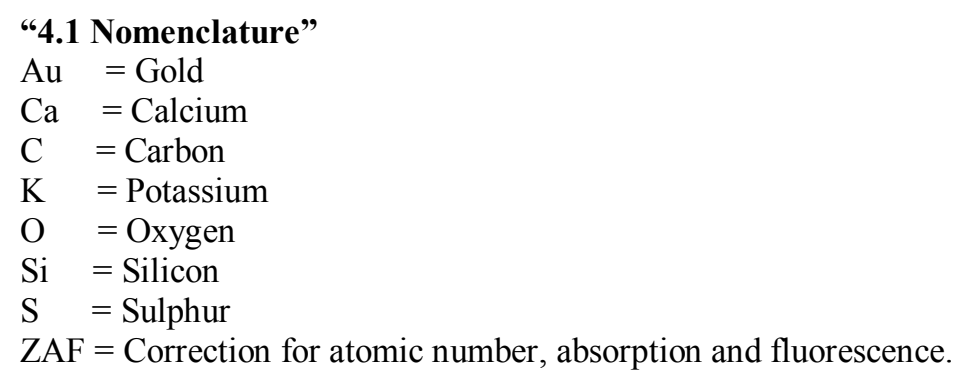

\section{Reference}

[1]. Y.S.Yun, D.Park, J.M.Park and B.Volesky, Biosorption of trivalent chromium on the brown seaweed biomass, Environmental Science and Technology, 35, 2001, 4353-4358.

[2]. H.A.Hegazi, Removal of heavy metals from wastewater using agricultural and industrial wastes as adsorbents, Housing and Building National Research Center, 9, 2013, 276-282.

[3]. S.Naeem, U.Zafar, A.Altaf and A.Inayat, Adsorption studies of $\mathrm{Cr}(\mathrm{VI})$ on rice husk ash, Journal of the Chemical Society of Pakistan, 31(3), 2009, 379-382.

[4]. M.S.Salman, Removal of sulfate from wastewater by activated carbon, Al-Khwarizmi Engineering Journal, 5(3), 2009, 72-76.

[5]. O.A.Wahab, A.E.Nemr, A.E.Sikaily and A.Khaled, Use of rice husk for adsorption of direct dyes from aqueous solution: A case study of Direct F. Scarlet, Egyptian Journal of Aquatic Research, 31(1), 2005, 1-11.

[6]. M.R.H.Mas Haris, N.A.Abdul Wahab, C.W.Reng, B.Azahari and K.Sathasivam, The sorption of Cadmium (II) ions on mercerized rice husk and activated carbon, Turkish Journal of Chemistry, 35, 2011, 939-950.

[7]. I.Nhapi, N.Banadda, R.Murenzi, C.B.Sekomo and U.G.Wali, Removal of heavy metals from industrial wastewater using rice husks, The Open Environmental Engineering Journal, 4, 2011, 170-180.

[8]. A.Mittal, L.Kurup and J.Mittal, Freundlich and Langmuir adsorption isotherms and kinetics for the removal of Tartrazine from aqueous solutions using hen feathers, Journal of Hazardous Materials, 146, 2007, 243-248.

[9]. M.Dutta, T.Ray and J.K.Basu, Batch adsorption of fluoride ions onto microwave assisted activated carbon derived from Acacia Auriculiformis scrap wood, Archives of Applied Science Research, 4(1), 2012, 536-550.

[10]. A.K.Bhattacharya, S.N.Mandal and S.K.Das, Removal of $\mathrm{Cr}(\mathrm{VI})$ from aqueous solution by adsorption onto low cost nonconventional adsorbents, Indian Journal of Chemical Technology, 13, 2006, 576-583.

[11]. N.Renugadevi, R.Sangeetha and P.Lalitha, Kinetics of adsorption of methylene blue from an industrial dyeing effluent onto activated carbon prepared from the fruits of Mimusops Elengi, Archives of Applied Science Research, 3(3), 2011, 492-498.

[12]. S.M.Gude and S.N.Das, Adsorption of chromium (VI) from aqueous solutions by chemically treated water hyacinth Eichhornia crassipes, Indian Journal of Chemical Technology, 15, 2008, 12-18.

[13]. Z.Aksu, Determination of the equilibrium, kinetic and thermodynamic parameters of the batch biosorption of nickel (II) ions onto chlorellavulgaris, Process Biochemistry, 38, 2002, 89-99.

[14]. A.M.Nurul, K.Satoshi, K.Taichi, B.Aleya and K.Hideyuki, Removal of arsenic in aqueous solutions by adsorption onto waste rice husk, Industrial Engineering and Chemical Research, 45, 2006, 8105-8110.

[15]. M.Mohapatra, S.Khatun and S.Anand, Adsorption behavior of $\mathrm{Pb}(\mathrm{II}), \mathrm{Cd}(\mathrm{II})$, and $\mathrm{Zn}$ (II) on NALCO plant sand, Indian Journal of Chemical Technology, 16, 2009, 291-300.

[16]. P.Senthil Kumar and R.Gayathri, Adsorption of $\mathrm{Pb}^{2+}$ ions from aqueous solutions onto Bael tree leaf powder: Isotherms, kinetics and thermodynamics study, Journal of Engineering Science and Technology, 4(4), 2009, 381-399. 
[17]. I.G.Shibi and T.S.Anirudhan, Kinetic and equilibrium modeling of adsorption of cobalt (II) from aqueous solutions onto surface modified lignocellulosics (Musa paradisiaca), Indian Journal of Chemical Technology, 13, 2006, 567-575.

[18]. S.Arivoli, M.Sundaravadivelu and K.P.Elango, Adsorption of $\mathrm{Fe}(\mathrm{II}), \mathrm{Co}(\mathrm{II}), \mathrm{Ni}(\mathrm{II})$ and $\mathrm{Cu}(\mathrm{II})$ ions onto a low cost activated carbon: Equilibrium, kinetic and thermodynamic studies, Indian Journal of Chemical Technology, 15, 2008, 19-28.

[19]. P.Rohini Kumar, M.Venkateswara rao, N.Chitti babu, P.V.Ravi Kumar and P.Venkateswarlu, Utilization of Erythrina variegate orientalis leaf powder for the removal of cadmium, Indian Journal of Chemical Technology, 16, 2009, 308-316. 